\title{
Design And Implementation Electrical Wheel Chair For Disable Able To Stairs Climbing By Using Hydraulic Jack
}

\author{
Abdal-RazakShehab, Ph.D. \\ Dept. of Electrical engineering, Kufa University, Republic of Iraq
}

\begin{abstract}
In this studying we present the designing and implementation of an electric chair for disabled persons, has the ability to rise on stairs with automatic controlling. The chair can be controlled to move in all directions and to raise the ramp and stairs with different degrees. The chair works with DC voltage source (Battery) can be recharged to work for long times. The design suggested has suitable size to be used in streets hospitals and home (width $=88 \mathrm{~cm} \&$ length $=125 \mathrm{~cm}$ ) also, can work with users weight reach to $90 \mathrm{~kg}$. It is also economically suitable comparing with that in markets as the cost of normal wheelchair walk only on the planes exceed 1300\$, while our chair cost is about 600\$ for one piece and this cost may be halved for a line of production.

The stability problem solved in this studying using the hydraulic jacks with electrical controlling by using the angle measuring devices. The previous studying and designs where of complex design and with high cost while this design is specialized to be simple and of easy implementation .
\end{abstract}

Keywords: Design, Electrical Wheel Chair, Hydraulic Jack

\section{Introduction}

A chair with wheels designed as a replacement forwalking is known as wheel chair. This is used for movement of physically disabled, elder people, childrenwho have difficulty and are unable to walk. This device comes in many variations like self-propelled, propelledby the motor or with the help of an attendee to push Figure 1shows the parts of rigid frame and Xframe wheel chair and its parts [1].

The disabled human are an important part of the society that should be given the humanity help to increase their taking part in the practical and scientific fields. So that it becomes so necessary to work hard to help this part of society to get better live.There are different means of help as the different disability types and the varying needs of daily functions. May be the ability of movement is considered as the most important daily functions which any human need it because it is the base to perform the different works, so that many means of movement are prepared which used by the disabled by himself or by the others help to get its purpose.The wheelchair is one of the most popular means and most activity to give the disabled human the wanted movement.And for importunacy of this wheelchair for this part and for increasing the disabled comfort and to make chair using more easer a great deal was taken to develop each part in it and many designs and inventions were done with different speeds and the using way. Also an additional part where added to the chair to be used in another maters as crossing the blocks. This method of drive gives a lower top speed than rear wheel drive chairs, but offers agood turning capability. The drive wheels are in front of the center of gravity while therear wheels are casters [2]. Various electric wheelchairs with computer-controlledmechanism have been developed in the recent years such asNav-Chair" [3-4]. These electric wheelchairs may use a" broad variety of sensors such as ultrasonic and infrared with several desired control devices such as joystick pressure pads, etc. in order to provide ease and comfort [5]. Electric wheelchair systems integrated with customized usercan make the function and controlling of a wheelchair muchsimpler and safer and make it more stable and handy fordisabled persons $[6,16]$. From the previous points the aim of this research is to develop the ability of the wheelchair by providing the ability of raising a stairs with different slop angles and with automatic control by using two rubber tracks to be connected between the wheels in such away becomes able to walk on stairs and low cost as compare with previous studying and designs where of complex design and with high cost while this design is specialized to be simple and of easy implementation. These controls helpalmost all categories of disabled persons to derive the wheelchair easy and safe.

The rest of the paper is organized as follows: Section IIoutlines a general idea of the overall system operation. Thedetailed discussion of the system is giving in Section III. TheFurthermore, a discussion about stability is also presented in fourth. Finally, electronic controlling circuit and the conclusionis presented in last Section. 


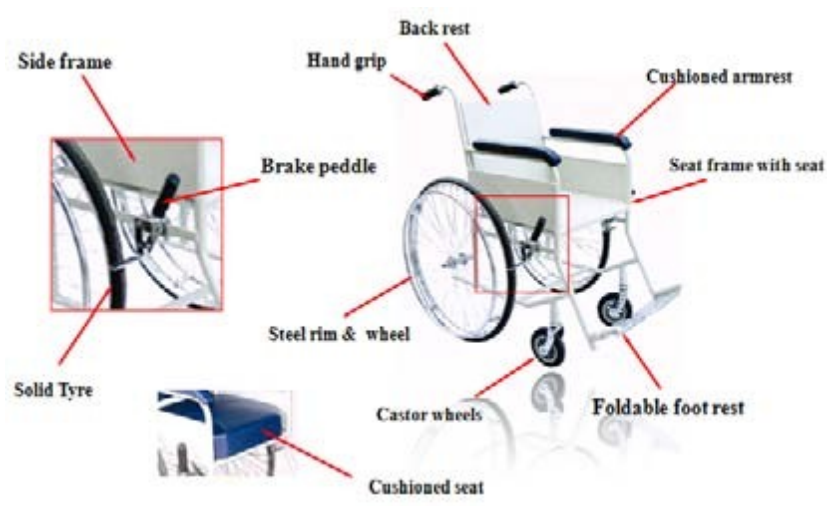

Fig. 1 Nomenclature of a rigid frame wheel chair
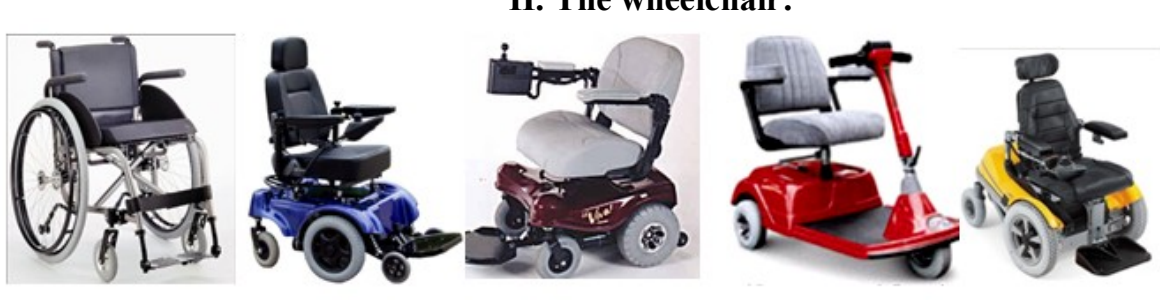

Figure (2) shows some of wheelchairs types

\section{2-1: Types of wheelchairs:}

There are many types of wheelchairs and every one designed for some purpose .Seating dimensions and cushion characteristics tests and reporting techniques are covered in ISO standards 7176-7 and 16840-2 [7,9],

and in general there are two kinds of wheelchairs:

1-Mechanical (Manual) wheel chair:

These kinds of chairs requires human potential to move, and if the disabled was tired or couldn't push himself by couching the two big wheels it is available to ask somebody to help him in moving chair but studies indicate that wheelchair skills training for manual wheelchair users is efficacious, safe and practical[8], it includes the following types:

a. Standard Wheel Chair.

b. Folding Light Weight Wheel Chair.

c. Rigid frame wheel chair.

d. special positioning wheel chair.

2- Powered Wheel Chair

It's defined as a tool has wheels moved by a battery, and it's prepared for medical purposes to provide the movement for disabled human. This type of wheelchairs contains a group of instruments and control devices in such a way that the disabled use only his hand to give the chair an order to move forward or backward or in any required direction, and it is two types :

1. Conventional Power Wheel Chair

This type have a base contains the motor and battery and four wheels at least in addition to chair system which connected to the top of base . The wheelchair controlled by (Joystick) moved by hand. And this type usually has heavy weight, and it classified into following:
a. Rear Drive Power Chair
b. Front Wheel Drive Power Chair
c. Mid- Wheel Drive Power Chair

2- Three or four wheels Scooter.

2-1: Disadvantages of wheelchair: The wheel chair is considered to be the best of the available instruments to help the disabled as it provides a big freedom to move, but there are some problems makes its abilities limited: 
1. The user cannot walk with it for long distances without taking some break to take some rest.

2. It doesn't have the ability to raise the curb.

3. The user couldn't take the things from the high roofs and also couldn't stand with the same level of the speaker man.

4. The chair movement is so hard in the narrow places and it is impossible in the unpaved ways.

5. The user cannot move for the bed or any other place only with the other help.

\section{Viewing For The Main Parts Of Machine}

So as to give clear look for the machine we divide its part into the following:

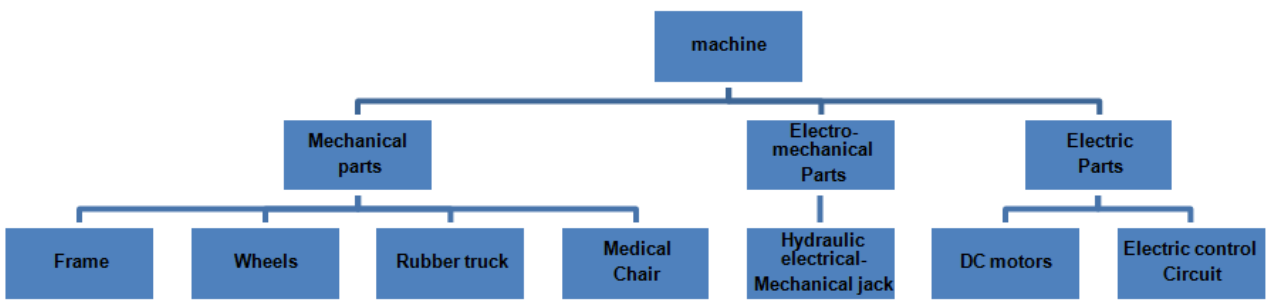

\section{1: the mechanical parts:}

\section{3-1-1: frame:}

It is used to give the mechanical supporting for the machine as shown in figure (3).

It is designed from the iron so as to be strong enough to carry the desired weight (60-90) $\mathrm{Kg}$.

Many shapes can be used for our design but the suitable one is that with very simple construction as shown in figure below:

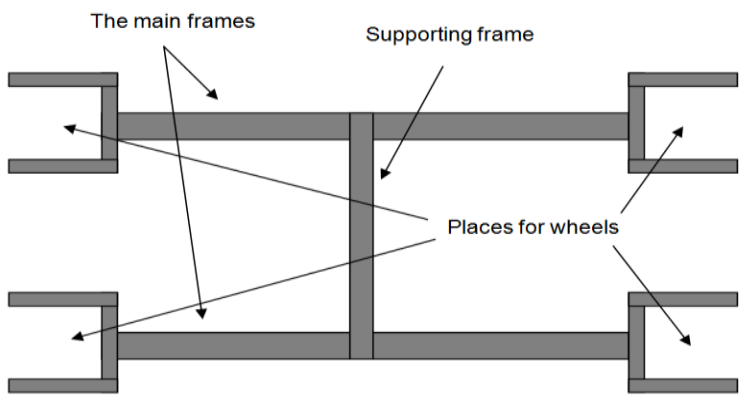

Figure (3) shows the frame of the base of chair

One disadvantage gained from last design is the high weight of this frame which must be small as possible because this frame weight will be added to the net weight of the machine.

Another factor should discussed is the dimensions of the frame which also must be smaller as possible to give the machine the ability for moving through the narrow places.

The world standard for the stairs is the following:

1. The width $=100 \mathrm{~cm}$ (as minimum).

2. The slope $=45$ degree ( as maximum).

3. The middle base of the stair $=1$ squared meter (as minimum).

It is clear that the width of the frame should be less than $1 \mathrm{~m}$,(say $90 \mathrm{~cm}$ as an ordinary value).

As we say before the size of frame must be small as possible so that the length should be short, but for stability purposes this length may be increased with limited range.

\section{3-1-2: wheels:}

After looking for the frame we see that we need four wheels with the following specifications:

1. Light weight: as its weight will be added to the total machine weight so that we can use the aluminum as example for its light weight.

2. suitable diameter: and it is determined by two factors :

The ability of raising the normal stair with normal size $(20 * 30) \mathrm{cm}$ where the increasing in diameter will make the rising on large stair more easer. 


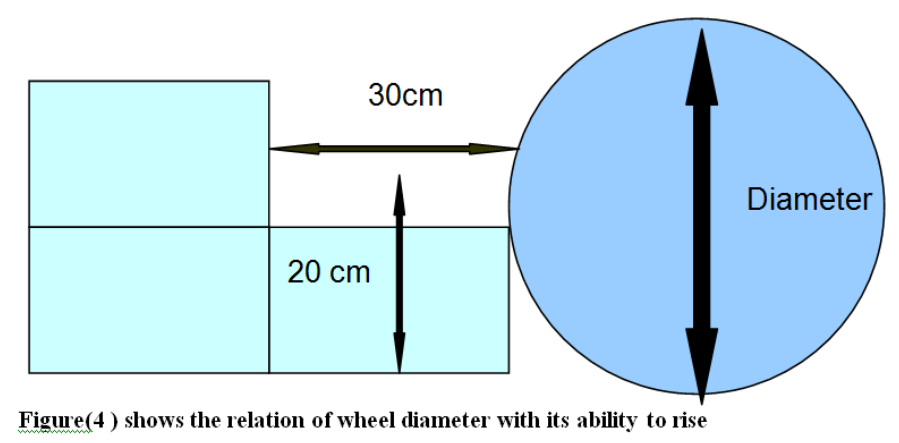

B. The weight: as increasing in diameters will increasing the weight and that unwanted as discussed above.

3. Designed with some way to connect to the rubber track.

\section{3-1-3: rubber truck:} the plan places.

Its function is to help the machine to raise the stairs in addition to the normal function of walking on

The rubber truck and according to its functions should has the following specifications:

1. With suitable length and width so as to be connected between each sided wheels.

2. Having friction factor make it able to be fixed on the slopes and stairs when the machine is stopping or running.

3. Having enough strength to avoid its damage when drawing the heavy machine with the disabled human on it.

4. it should has a teeth with the ground side to give the machine suitable friction with ground and prevent the machine from falling .

\section{3-1-4: medical chair:}

All the previous parts will forming the base with each other, then a medical chair will be added on this base to finish the mechanical part figure (5) shows the medical chair used in this research.

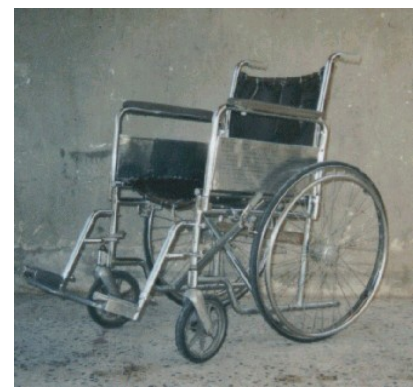

Figure(5)The medical chair used in this research

Many other designs of chairs can be used instead of this, but may that types of chair be harmful for the disabled from the medical point of view especially that the disabled sitting for long time on this chair.The users are the most knowledgeable about their own physical, social and cultural needs [10].

We chose the medical chair for the following reasons:

1. Its light weight ( about $15 \mathrm{~kg}$ ) and that will help us in two points :

a. It will reduce the total weight of the machine.

b. It will make the control more ease.

2. its low cost

3. it is suitable from the medical point of view.

4. it has very suitable size to be connected to the base .

\section{3-3:Electromechanical parts:}

3-3-1: Hydraulic electrical-Mechanical jack:

The main purpose of it is to control in the chair position and to generate the stability.

Stability is the main problem and it will discussed next in chapter.

The idea of hydraulic jack can be shown as in figure (6) below: 


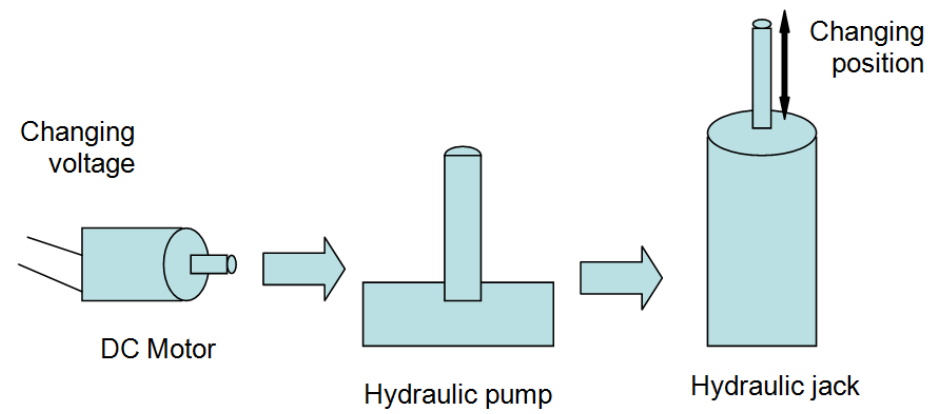

Figure 6) the hydraulic jack working

\section{3-2 electric part:}

\section{3-2-1: DC Motor:}

As discussed before the drive (D.C) motor will help the disabled so as not to making any potential except controlling the gear box, the of motor power are calculated with respect to the weights of patient and our tool and considering the ramp of stair.

$r$

\section{3- 2--2: Electric control circuit:}

It controls the following parts:

1. The two DC motors.

2. Three hydraulic jacks.

\section{Stability}

So as to make the chair rise the stairs we have to generate enough stability for it.

All the previous researches were focus on the stability problem, how to solve it and how can we get the highest level of stability.In this section well see how the researches and companies find solution for this problem and what are the disadvantage of their solutions and how we improve that studying to reach what we have now.Static stability and overall dimensions, mass and turning space tests and reporting techniques are covered in ISO standards 7176-1, 7176-5 and 7176-7 [7, 9].

\section{4-1: Stability of bodies on slops}

If we put a weight on a slope (either plane or stair) the body will be not stable and need enough friction to stay as shown in figure (7) below:

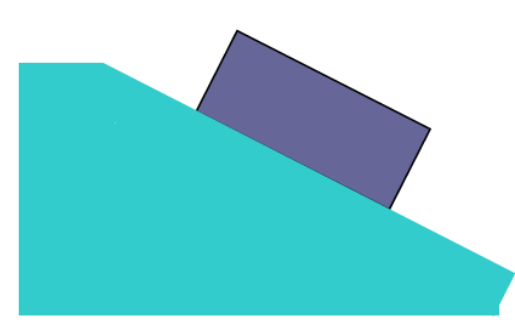

(a) Stairs

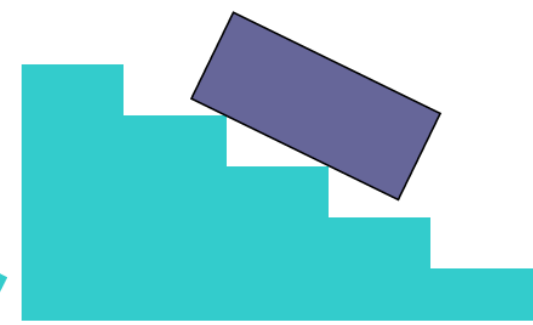

(b) slop

Figure (7) the normal weight on slop and stairs

If we produce enough friction with the surface the body will not fall down but, the real problem is that when the shape of the weight is changed as shown in figure (8) below:

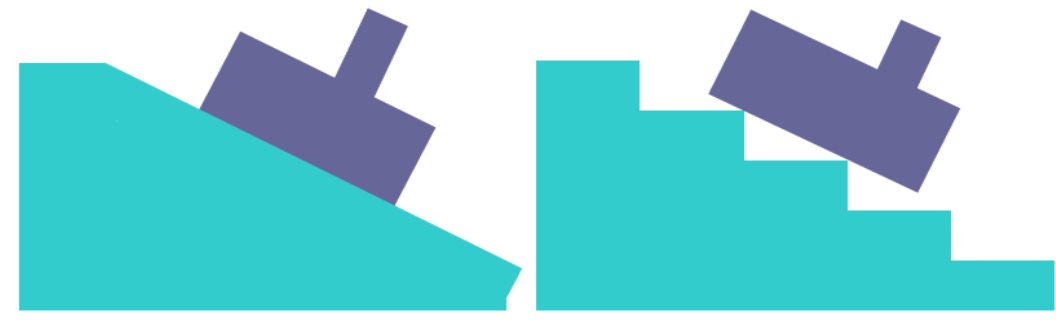

Figure (8) the unbalanced weight on slop and stairs

In this case the body is unbalanced and it couldn't stay on stairs or slop so that we loss the stability here. We have many methods to solve this problem as following: 
1- by changing the shape of body and trying to rearrange the weight in the total area with the same manner as shown below:

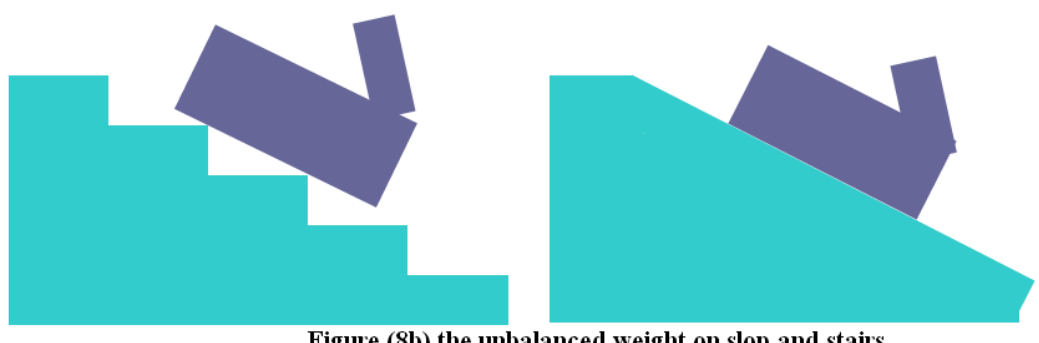

Figure (8b) the unbalanced weight on slop and stairs

by adding some fixing tool to fix the body as shown below:
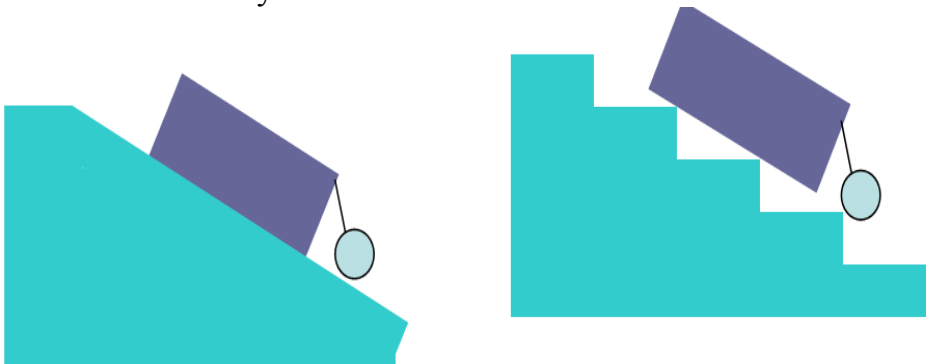

Figure (8c) the unbalanced weight on slop and stair

And there are many other ideas well focus on these two ideas which explained in simple way.

\section{4-2: solving stability problem}

In this research we solve the stability problem by using the hydraulic jacks controlled by an electrical circuit and angle measuring device.

\section{4-2-1: controlling of the hydraulic jacks}

In additional to the motors there are three hydraulic jacks to be controlled, so as to maintain the stability as shown in figure (9) below:
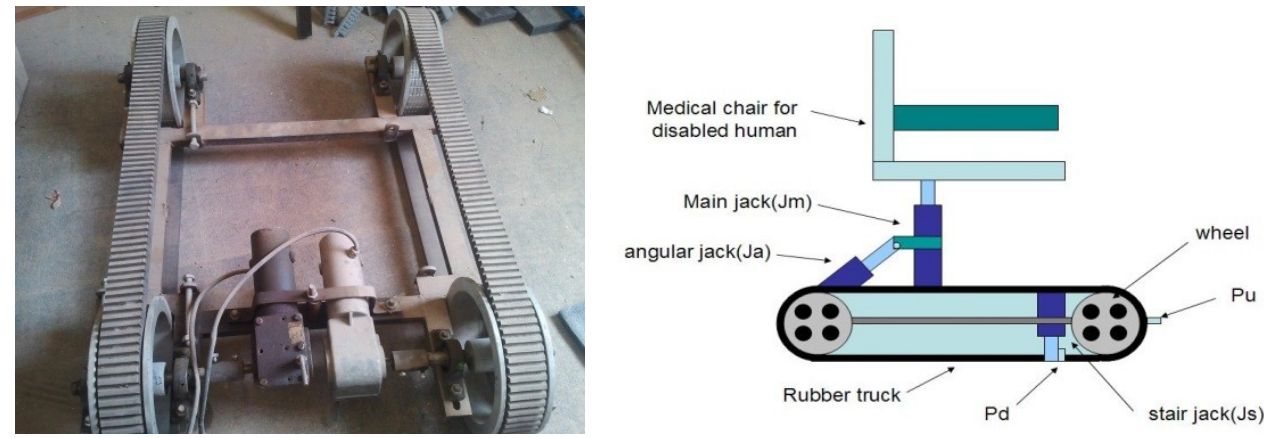

Figure(9) shows the main part of the electric chair

\section{4-2-2: the function of jacks}

1. main jack $(\mathrm{Ja})$ :

the main jack is to lift the chair up and put it down as in figure (10) follow: 

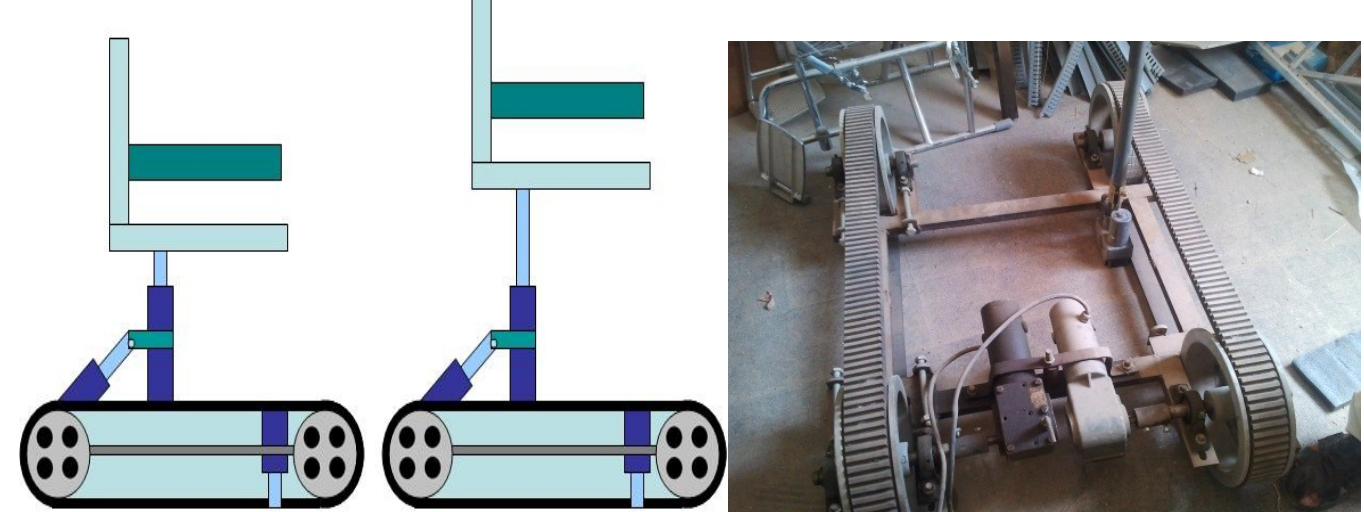

Figure (10) shows the main jack function in the electric chair

\section{2- stair jack(Ja):}

the stair jack should lift it only from its forward part :

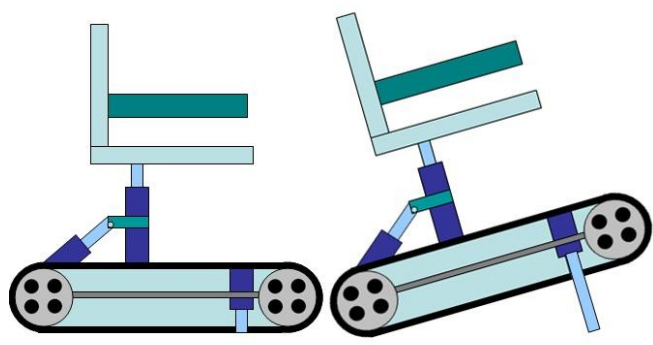

Figure( 11) shows the main part of the stair jack in electric chair

\section{3-Angular jack(Ja):}

the main purpose of it is to move the chair in forward and backward directions with an angle ( may reach to 45 degree) .
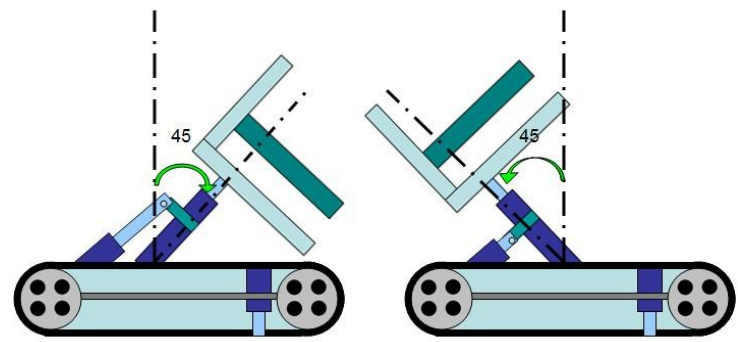

Figure(12 ) shows the main function of the angular jack in electric chair

\section{4-3: the working of hydraulic jacks:}

In this part we will take the case when the chair rising a stair.

- at the normal operation on plane, the machine is in working due to the controlling gear box which can be easily controlled by the disabled .

- when the machine face a stair, at the time machine touch the first stair of the stairs a push bottom (working as a sensor) will be closedas shown below: 


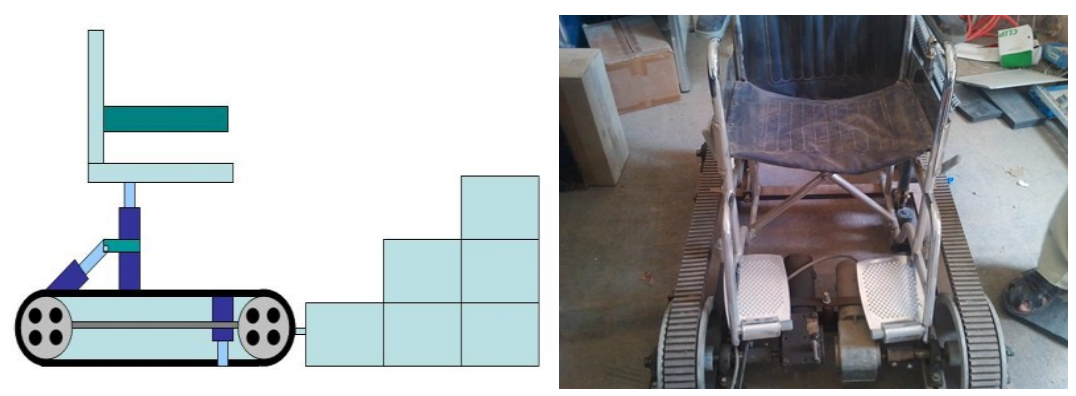

Figure(13) the instant chair touch stairs

And according to this bottom the following should happen:

1. The left and right motors should turn off independently on the gear box situation.

2. The stair jack should turn on and lift the forward part of the chair as explained before.

3. After the stair jack works, the chair will not be perpendicular to the ground so that the angle measuring device will work to turn the stair jack off and turn the chair to the forward direction and rebalance its self to be perpendicular to ground again.

4. the chair jack will work again to lift the forward part of the chair and again the angle measuring device will work again and so on until the forward wheel being on the first stair as shown below :

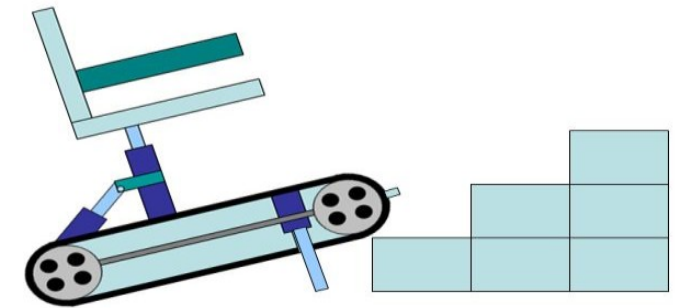

Figure(14) instant chair on the first step(stair jack is open)

- at the time the forward part reach the first stair the push bottom will turn on again and the following should be happened:

1. the stair jack will enclose .

2. the motors turn on again and the machine continue to rise the stairs at the same time the chair arrange its self-using the angle measuring device until reach the final stair .

- now, the machine going back in reverse operation and the same steps will occurs again .

The angular jack works and the chair back to be perpendicular to ground

\section{Electronic Controllingcircuit}

After we understand the movement of hydraulic jacks and the movement of the DC motors, we are going to design suitable electric circuit to do that.

\section{5-1: choosing suitable controlling method:}

There are many ways to make this design an example given below:

1. by using the DC contactors : it is very useful way to control loads like motors but it has problem is the high cost especially with high current ( may reach to 30A) .

2. by using the microcontroller : it is also good way to control but we have simple controlling and this way usually used with the complex applications .

3. by using direct manual controlling : it is good way as its low cost but it has big disadvantage where the disabled need long time and accuracy to learn its driving .

4. by using automatic controlling using power electronic devices (as diodes and SCR's ) : and we see that it is the most suitable way for the following reasons :

a. its suitable cost.

b. It's simple construction.

c. Its small size.

d. The availability of its component commercially. 


\section{5-2: construction of the electric circuit}

So as to simplifying the explanation of the circuit we divide it into small circuits that we joining it.

\section{5-2-1: left and right motor control}

If we connect the circuit as shown below:

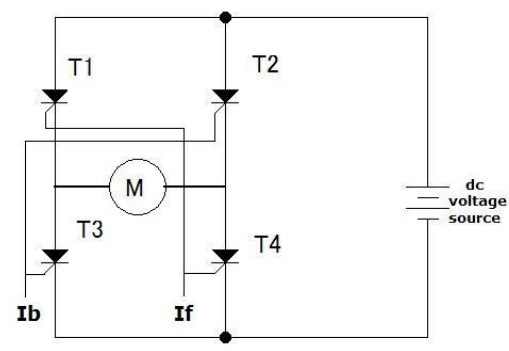

Figure (15) the electric circuit for one motor

As we see the circuit similar to the full wave bridge rectifier but here we use the dc voltage source directly.So as to run the motor in forward direction we should trigger T1\&T4 together so that the current passing from left to right in motor. Similarly, when we want to run the motor in reverse direction T2\&T3 should be triggered together so as to make the current passing from right to left in the motor. All that for only one motor (left or right motor), but now we want to control them together so that two circuits similar to that in figure should be used. Now, we design another circuit to control the triggering of the two circuits (left and right) as shown below:

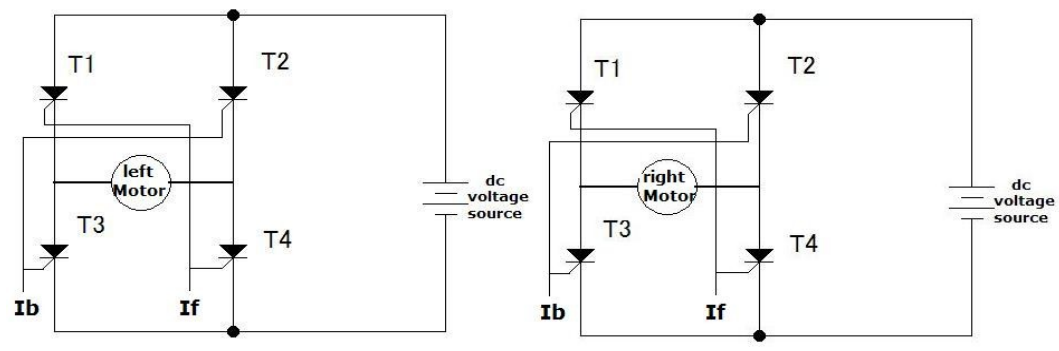

Figure(16) right and left D.C motor circuits

The control of triggering for the two circuits is shown below:

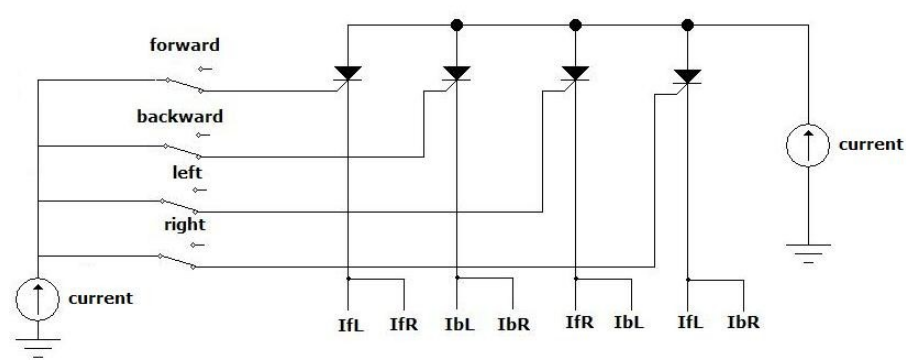

Figure(17) the electric circuit of trigger

Where:

IfL is the forward triggering current of left motor.

IfR is the forward triggering current of right motor.

$\mathrm{IbL}$ is the backward triggering current of left motor.

$\mathrm{IbR}$ is the backward triggering current of left motor.

The forward, backward, left \& right pushes can be connected to form control gear box as show below: 


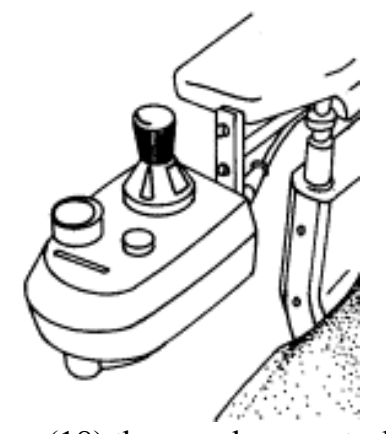

Figure (18) the gear box controller

\section{5-2-2 : hydraulic jack control circuit}

After we see the work of push bottom, it should be put as below:

1. As it turn the motors off, close attachment should be put through the current passing path (i.e. in series with the two motors ).

2. as it turn the stair jack on, open attachment should be put in the direction of the stair jack.

For hydraulic jacks, the following should occurs:

1. angular jack : it depends directly on the angular measuring device which is shown below :

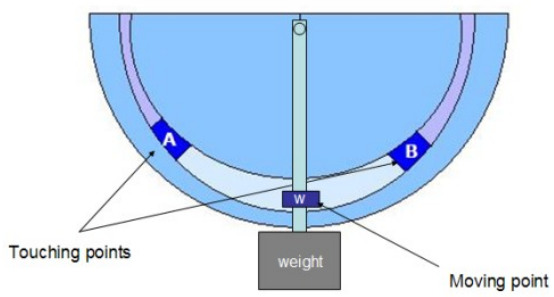

Figure(19) the angle measuring device

When the chair moving backward W\&A points contact and when the chair moving forward W\&B points contact and there is no contacting if the chair is perpendicular to ground. So that (WA) \& (WB) will control the movement of the angular jack with lengthen and shorten moving.

2. Main jack: its function is to prevent the touching of the chair with its base so that it work at the same time with the angular jack so that (WA) \& (WB) also controls the movement of the main jack .

3. Stair jack: said we said before it works and controlled by the push bottom.

\section{5-2-3: the electric circuit of jacks:}

According to the last section the electric circuit of jacks is shown below:

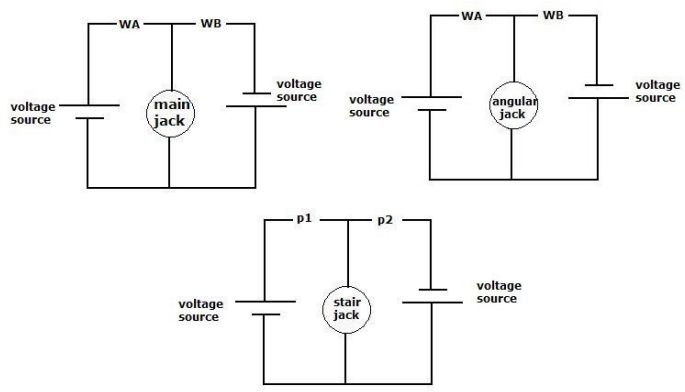

Figure( 20) the electric circuits of the jacks

Also, the push bottom must be in the direction of the motors passing current as shown below : 


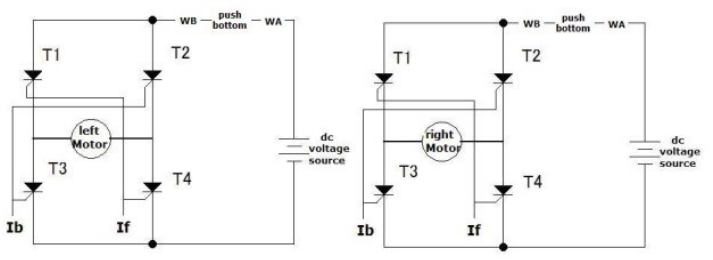

Figure( 21) the modulated motors circuit

\section{Conclusions:}

Clearly we can see the presented design is a very simple from a point view of implementation it is also economically suitable comparing with that in markets as the cost of normal wheelchair walk only on the planes exceed $1300 \$$, while our chair cost is about $600 \$$ for one piece and this cost may be halved for a line of production.

The stability problem solved in this studying using the hydraulic jacks with electrical controlling and using the angle measuring devices.

The previous studying and designs where of complex design and with high cost while this design is specialized to be simple and of easy implementation.

\section{References:}

[1] Batavia, M., PH. D (1998), “ The wheel chair evaluation a practical guide”, ISBN 0-7506-7037-1

[2] New Definition, http://www.assistive-technology.ca/newdef2.htm

[3] J.D. Nisbet, I.R. Loudon and J.P. Odor, "The CALL Center smart wheelchair". In Proceedings of 1st International Workshop on Robotic Applications to Medical and Health Care, 1988, Ottawa, Canada.

[4] HåkanNeveryd and Gunnar Bolmsjö, "WALKY, A mobile robot system for the disabled". In Proceedings of the 4th International Conference on Rehabilitation Robotics (ICORR), June, 1994 Wilmington, Delaware, USA, pp. 137-141.

[5] M3S: A general-purpose multiple-master multiple-slave intelligent interface for the rehabilitation environment, International Standards Organization, 1995.

[6] J. M.Ford and S. J. Sheredos, "Ultrasonic head controller for powered wheelchairs". Journal Of Rehabilitation Research and Development, 1995, 32(3): pp. 280-284.

[7] ISO 7176-24:2004. Wheelchairs - Part 24: Requirements and test methods for user-operated stair-climbing devices. Geneva,International Organization for Standardization, 2004 (http://www.iso.org/iso/iso_catalogue/catalogue_tc/catalogue_detail.htm?csnumber=31276, accessed 9 March 2008).

[8] B est KL et al. Wheelchair skills training for community-based manual wheelchair users: a randomized controlled trial. Archives of Physical Medicine and Rehabilitation, 2005, 86:2316-2323.

[9] ISO 7176-7:1998. Wheelchairs - Part 7: Measurement of seating and wheel dimensions. Geneva, International Organizationfor Standardization, 1998 (http://www.iso.org/iso/iso_catalogue/catalogue tc/catalogue detail.htm?csnumber=13783,accessed 9 March 2008).

[10] Krizack, M. The importance of user choice for cost-effective wheelchair provision in low-income countries. In: Proceedings, 12 th World Congress of the International Society for Prosthetics and Orthotics, Vancouver, 29 July - 3 August 2007. Copenhagen, International Society for Prosthetics and Orthotics, 2007.

[11] S heldon S, Jacobs NA, eds. Report of a Consensus Conference on Wheelchairs for Developing Countries, Bangalore, India,6-11 November 2006. Copenhagen, International Society for Prosthetics and Orthotics, 2007 (http://homepage.mac.com/eaglesmoon/WheelchairCC /WheelchairReport_Jan08.pdf, accessed 8 March 2008).

[12] M cNeal A, Cooper RA, Pearlman J. Critical factors for wheelchair technology transfers to developing countries - materials anddesign constraints. In: Proceedings of the 28th Annual RESNA Conference [CD-ROM]. Atlanta, GA, RESNA, 2005:25-

[13] Chung-HsienKuo, Ting-Shuo Chen, Jiann-Jone Chen, Yang-Hua Lin, Wen-Yu Liu, "Human-centered Wheelchairs: Bimanual GlidingInterface with Heart Rate Monitoring", Kaohsiung, Taiwan, pp: 208 - 213 , 2012.

[14] RiniAkmeliawati, Faez S. Ba Tis, Umar J. Wani, "Design and Development of a Hand-glove Controlled Wheel Chair", InternationalConference on Mechatronics (ICOM), Kuala Lumpur, Malaysia, pp: 1 - 5, 2011

[15] Sho Yokota, Hiroyuki Tanimoto, JunkiHeguri, Kyohei Yamaguchi, Daisuke Chugo, Hiroshi Hashimoto, "Improvement of AssistiveWheelchair Caster Unit for Step Climbing", IEEE International Symposium on Robot and Human Interactive Communication, Paris, France, pp: 240 - 244, 2012.

[16] Giuseppe Quaglia, Walter Franco, Riccardo Oderio, "Wheelchair.q, a motorized wheelchair with stair climbing ability", Mechanismand Machine Theory, pp: 1601-1609, 2011 